\title{
Identifying Similarities and Differences on How Deaf and Hard of Hearing Students Learn New Vocabulary Knowledge
}

\section{Faisl M. Alqraini}

Asst. Prof., Prince Sattam bin Abdulaziz University, Saudi Arabia,f.alqraini@psau.edu.sa

\begin{abstract}
This article details a study that was designed to explore the differences and similarities with deaf and hard of hearing students regarding learning new vocabulary knowledge through the sign language. The purpose of this study was to know whether or not students who are deaf and hard of hearing are similar to their hearing peers when learning new vocabulary knowledge. Also, the study explores what support teachers need in order to make the learning environment more effective and helpful. The study took a place in the United States in an urban public school's fourth grade reading classroom. No research studies have employed ethnographic methods to provide information about how deaf and hard of hearing students learning new vocabulary knowledge in the classroom. An ethnographic approach can provide insights into the learning and teaching of literacy that quantitative methods alone cannot illustrate. The research findings show that deaf students faced many challenges in comprehending many words. However, they are qualitatively similar in terms of the learning process, but quantitatively delayed. Additionally, the teachers need additional support in applying technology and co-teaching while teaching deaf or hard of hearing students.
\end{abstract}

Keywords: vocabulary knowledge, deaf and hard of hearing, special education, learning, hearing

\section{INTRODUCTION}

Developing reading skills has been the goal of educating the deaf and hard of hearing since the founding of the first school for the deaf in the United States in 1817 (Stewart \& Clarke, 2003). Vocabulary knowledge is the first step in learning how to write and read independently. Many communication approaches have been used to achieve this particular goal; however, poor reading skills are still an issue for deaf students. It is well documented that the majority of students who are deaf and hard of hearing experience delays in reading skills and that most of them graduate from high school with reading skills at the fourth-grade level; some, below (Luckner et al., 2005/2006). Spencer and Tomblin (2009) have indicated that $30 \%$ of deaf students often leave high school in the United States illiterate.

Citation: Alqraini, F. M. (2018). Identifying Similarities and Differences on How Deaf and Hard of Hearing Students Learn New Vocabulary Knowledge. International Journal of Instruction, 11(4), 6174. https://doi.org/10.12973/iji.2018.1145a 
One of the many obstacles to reading and comprehending written content for deaf students is the delayed acquisition of vocabulary because most learning, especially in the first years, takes place through indirect conversations with parents, playing with peers, conversations, accidental listening, and watching TV (Luckner \& Cooke, 2010). Because they cannot participate in auditory learning, deaf students are deprived of these beneficial experiences through which language is typically developed. This limited vocabulary, in turn, results in difficulties in the learning process. However, some students who are deaf and hard of hearing learn to read at the grade level. Moreover, some become successful writers (Luckner et al., 2005/2006). In this paper, I share research that documents and explores how deaf and hard of hearing students learn new vocabulary knowledge over sign language.

\section{The Goals of the Study and Research Questions}

The aim of this study was to explore and gain in-depth knowledge of how deaf and hard of hearing students learn new vocabulary knowledge through sign language, and what support the teacher needs from the school in order to make the learning environment more effective and helpful. The research questions were as follows:

- How do deaf and hard of hearing students learn new vocabulary knowledge through sign language?

- How do deaf students make progress in the classroom and what challenges do they encounter?

- What additional instructional support does a teacher need from the school?

\section{Theoretical Framework}

Vygotsky (1978) argued that social interaction with knowledgeable individuals lead increasing thinking skills in children which is "all higher mental functions are internalized by social relationships" (pp. 98). Also, Lave and Wenger (1991) pointed out that individuals' knowledge was built and shaped by the activities that they had been a part of in community participation. Moreover, Lave and Wenger looked at learning as not an isolated activity, but as one that occurs with others over joint activity. Therefore, individuals who have more knowledge than others can assist and uphold new learners in building meaning until the new learner functions independently (Lee \& Smagorinsky, 2000).

Also, the qualitative similarity hypothesis theoretical framework (QSH) (Paul, 2010), believes that the acquisition of literacy skills by those who are deaf and hard of hearing is qualitatively similar to that of those who have typical hearing; however, quantitatively it is delayed similarly to someone learning English as a foreign language. Thus, the vocabulary knowledge of deaf and hard of hearing students is quantitatively less than their typical literacy learners. The QSH strongly believes that students who are deaf and hard of hearing are able to learn like their hearing peers, but at a slower speed and rate, and they obtain smaller results in learning and need additional assistance services (Paul, 2010, 2012; Paul \& Lee, 2010; Paul \& Wang, 2012). They need more help to improve their reading skills, and the first step to reading is building vocabulary knowledge. 


\section{The Relationship between Vocabulary Knowledge and Reading Comprehension}

Researchers have realized for decades that vocabulary knowledge is a strong indicator of reading comprehension (Stahl \& Nagy, 2006). Therefore, there is no doubt that vocabulary knowledge plays a vital role in reading comprehension (Davis, 1944; McKeown \& Beck, 1988; Paul, 1989; Stahl \& Nagy, 2006; Williams, 2012; Paul, 1998). Since readers acquire the meanings from the text, the vocabulary that they know will determine how well readers comprehend print (Nagy, 2005).

The American National Reading Panel (NRP, 2000) pointed out that vocabulary is one of five main components of successful reading due to the necessity of vocabulary in comprehending the printed word. Vocabulary knowledge has also been found to be one of the most important variables in the reading success (Curtis, 2006). Paul (2009) found a strong correlation between vocabulary knowledge and reading comprehension. Students who performed well on reading vocabulary tests also performed well in reading comprehension. Trezek, Wang, and Paul (2010) indicated that the aim of reading is to comprehend the meaning of the text, whereas comprehension depends on the level of the vocabulary that a person possesses. Clearly, vocabulary knowledge is significantly dynamic in reading comprehension. Without vocabulary knowledge, reading comprehension will be impossible because it is vocabulary knowledge that determines reading comprehension.

Vocabulary knowledge has two main portions: depth and breadth. Both of these are fundamental to understand the connection between vocabulary knowledge and reading comprehension (Qian, 1999). Breadth of vocabulary knowledge is defined as vocabulary size, namely the number of words' meanings that a person knows (Paul, Stallman \& O'Rourk, 1990). Depth of vocabulary knowledge is defined as a learner's knowledge of words, including their meanings, figurative uses, and nuances (Paul, 2009; Paul, Stallman \& O'Rourk, 1990). Nagy (2005) stated that comprehension relies on depth and breadth of vocabulary knowledge. Breadth and depth of vocabulary knowledge play a significant role in reading comprehension because having a solid breadth of vocabulary indicates that the more words' meanings that the reader knows, the easier it is for him to understand and acquire the meaning of the text (Curtis, 2006). Depth of vocabulary knowledge, however, consists of "figurative usage of words, synonyms, antonyms, homonyms, analogies, and multiple meanings" (p.14). Depth of vocabulary knowledge deeply influences reading comprehension because when readers know words' meanings, this result in their having the conceptual frameworks related to the word meanings, which facilitates readers to comprehend the text (Paul, 1989).

\section{Obstacles of Learning Vocabulary Knowledge}

Research done by Lekberg and Spencer (2001) has shown that deaf students often experience delays in building their vocabulary knowledge; they also have smaller lexicons, acquire new words slowly, and have a small range of word contexts, which affects their learning of new terms. This means that a vicious cycle is created; it can be observed that limited vocabularies often affect reading comprehension, and these poor reading strategies limit the skills of the students to acquire enough knowledge from given contexts (deVilliers \& Pomerantz, 1992). 
Printed words are not often understood when some of the words do not exist in the vocabulary of the reader (Luckner \& Cooke, 2010). "As a result, it is often noted in the literature that reading comprehension is impeded if individuals do not know 90\%-95\% of the total words in the text" (Luckner \& Cooke, 2010, p. 39). Due to loss of hearing, deaf children often encounter difficulties with acquiring English vocabulary through the same method of learning that hearing children use (Luckner \& Handley, 2008). Since they cannot hear conversations, deaf children often encounter problems with the development of their English at the appropriate age level (Luckner \& Cooke, 2010). Deaf children also have problems that are related to multiple meanings of words, and they have to rely on local contexts to determine the appropriate meaning of a given word (Marschark, Lang, \& Albertini, 2002). Some studies have found limited English vocabulary and reading comprehension scores in children who are deaf compared with those with typical hearing (Singleto, Morhan, DiGello, Wiles, \& Rivers, 2004).

Additionally, in sign language, the connection between sign and print is not analogous (Mayer \& Wells, 1996). The way students look at vocabulary meanings in words may differ from the way they interpret meanings in sign language. Sign language is, in general, not exactly the same as the language that is found in print vocabulary because it is a spoken language, which is inherently not identical to written language; therefore, this has an effect on vocabulary development in deaf students (Hamm, 2010).

\section{METHOD}

The goal of this study was to explore and gain in-depth knowledge of how deaf and hard of hearing students learn new vocabulary knowledge through sign language, and what support the teacher needs from the school in order to make the learning environment more effective and helpful. The research questions were a) how do deaf and hard of hearing students learning new vocabulary knowledge through sign language? B) how do deaf students make progress in the classroom and what challenges do they encounter? And, c) what additional instructional support does a teacher need from the school? An ethnographic design was used in order to answer research questions.

\section{Research Setting and Participants}

The study was conducted in the United States at Elementary Urban Public School in East Coast. The deaf program in this school is an intensive program designed to educate deaf and hard of hearing students in the same setting as their hearing peers, which means they are fully mainstreamed with general education students, an integration made possible by the support of a teaching staff specializing in the education of the deaf and hard of hearing. The essential approach of this program is Total Communication (TC) and Oral Education (OE).

All educators in the program comply with the No Child Left Behind Act and more than $90 \%$ hold Master's degrees and have than 15 years of teaching experience in the domain of deaf and hard of hearing education. The main goals of the program are to provide professional diagnosticians alongside teachers and family to build up educational goals suitable for each student. 


\section{Participants}

The focus group was a fourth-grade reading classroom using the total communication method. The total communication method mainly uses spoken language and signs simultaneously. The group included six students who were severely to profoundly deaf including a black male student from a Somali background who came from a nonEnglish-speaking family, four white male students, and one white female student. Two students had received cochlear implants and four wore digital hearing aids in order to utilize their residual hearing.

The students' reading achievement levels on The Story Town Curriculum (TRC) were as follows: (a) two students are on the print concept level; (b) one student is on level C; (c) one student is on level G; (d) one student is on level E; and (e) one student is on level M. All students have individualized education programs (IEPs).

\section{Data Collection}

This study systematically gathered data via observations, field notes, documenting teacher's works, and interviews using audio recording. The data was collected over a one year period. The first visit took place on January and the last visit was at the end of November. Additionally, two recorded audio interviews were gathered each term; the first interview was 11 minutes while the second interview was 15 minutes long.

The goal of the observation process was to observe how deaf and hard of hearing students learn new vocabulary knowledge, what challenges the students encountered in the classroom in terms of learning new vocabulary knowledge, and what kind of support the teacher needed. Therefore, descriptive field notes were derived from the observations and interview in detailed documentation. Additionally, the researcher utilized the teacher's paperwork in order to analyze vocabulary level (depth and breadth), number of new vocabulary terms, and the difficulty level of vocabulary instruction.

Audio recording was used in order to interview the teacher, asking several types of questions that were derived from the literature review. Through the interview, it was easy to recognize the teacher's reasons for using certain teaching techniques and not others, and the reasons other techniques were not used.

\section{Analyzing the Data}

Data analysis was also conducted over reading storybooks in the classroom during observations. The data analyzed was based on recurrent activities and revealed the results of this study. Three themes of the data collection were highlighted and analyzed in order to answer the research questions. Analysis took place systematically and included describing sites and reading activities through narrative writing.

Using content analysis, the data was analyzed in the following three steps. The first step was gathering and preparing data collected in fieldwork in order to analyze interviews, field notes, and all materials that were used so that they could be written up.

The second step was to reread and review the fieldwork research to revise and refine the fieldwork materials, such as field notes and audiotapes, in order to connect the 
information included in the responses to the research questions. It was not beneficial to add all the information that was not related to the research questions.

The last step was beginning to write a detailed, narrative description of the findings, including details from the transcripts and discussing the significance of working with that group.

\section{FINDINGS}

An analysis of the observations, interview, field notes, and materials yielded three theme categories. The first theme is the teaching strategy (how deaf and hard of hearing students learn new vocabulary knowledge), the second theme is how deaf and hard of hearing students made progress in the reading classroom as well as their most challenging encounter, and the third theme is what kind of additional support the teacher needs in the classroom.

\section{Teaching Strategies}

The first theme, teaching strategy (how deaf and hard of hearing students learning new vocabulary knowledge), had a primary focus to identify the teacher's methods for teaching vocabulary to deaf students into the classroom. The research analyzed this theme based on recurrent activities. For example, the recurrent activities included reading storybooks entitled The Man who Walked Between the Towers and Fun in the $M u d$ in addition to other activities.

In the first activity, the teacher read and signed the story to the students while also displaying the book's pictures on a PowerPoint presentation as a way to link the students' attention with what she was reading and signing. Afterward, to make sure the students understood the story, the teacher listed some words that seemed unfamiliar to the children, such as wire, fiery, sway, astonish, and terrify. She then defined each word by providing an example and described how these words were pronounced using visual phonics. While she explained these words to the students, she reread the story and asked questions to ensure that they understood it. No other activities were involved in this lesson; all the teacher did was to explain the words' meanings to the students and show pictures related to those words.

Another recurrent activity involved teaching students new words, such as rut, mud, table, cable, gym, radio, pup, and fun. These words were taken from the storybook Fun in the Mud; however, the teacher wanted to make sure the students were able to understand the words before getting started. The teacher began teaching the words the same way that she had in the last activity, with no changes. She showed the students pictures and taught the words' syllables and pronunciations. She also showed how to spell each word using fingerspelling. The researcher asked the teacher about this strategy, and she answered:

I think that with deaf and hard of hearing students, repetition is key, and so I use that visual and take the visual away before asking questions. Then, you know, so they can become more comfortable with it, I always I relate all of my vocabulary to the words that we are either reading or seeing in sign. I think that is an important strategy, too. 
Additionally, I observed another activity that was related to teaching words, except that these words were not new to the students; this was a review of previous lessons. The main goal of the activity was to determine if students are able to recognize parts of speech (e.g., verb, noun, adjective, and pronoun). The teacher used the smart board to make three lines. The first line was for verbs, the second was for nouns, and the third was for adjectives. The students had to select a word and then move it to the appropriate section. For instance, if a word was a verb, it would be placed in the verb section, and if it was a noun, it would be placed in the noun section. All students were participating in this activity; some correctly placed words, and others made mistakes. This activity took around fifteen minutes. After that, the students moved to another table to do a similar activity on paper.

The researcher interviewed the teacher to determine if the teacher implemented other strategies (e.g., semantic elaboration models) of teaching vocabulary. The answer was:

At this point, we are not because the words are so simplistic. I think eventually that would be a good option, although ... I haven't used that this year.

Data interpretations revealed and asserted that the instructor's philosophy of imparting vocabulary knowledge was heavily focused on the repetition of new words. The strategy of providing deaf and hard of hearing students with definitions and showing them corresponding pictures is ineffective because it is based on memorization. Some scholars, such as Paul (1996), have even viewed this approach as ineffective for hearing students. Therefore, the implication is that emphasizing semantic elaboration models (e.g., semantic feature analyses, word maps and semantic maps) when teaching vocabulary can be very helpful with both hearing and deaf students. Such approaches enrich students' vocabulary knowledge in meaningful ways, beyond those of traditional teaching, which concentrates on repetition (Paul, 1996). Repetition is necessary, but it is not the main approach for teaching deaf students; these students need to see words many times, despite the fact that the content is not isolated.

Furthermore, the teacher cites her reasoning for not using semantic elaboration models is because the words being taught are so simplistic that there is no need to use this technique. If words are taught in an isolated context instead of integrating them through meaningful use, students will not be able to extend their vocabulary knowledge. Moreover, they will not be able to gain permanent ownership of these words because the terms will be saved in their short-term memory, which fades with time. Presenting words through activities such as semantic elaboration models will be more effective than repetition.

Thus, vocabulary lessons should be designed to support students' word learning through a combination of approaches, including direct instruction and incidental vocabulary instruction. These approaches assist students by producing multiple exposures to the vocabulary through practice and review.

\section{Student Challenges}

The second theme explored how deaf and hard of hearing students made progress in the reading classroom, what the challenges students encountered in terms of learning new vocabulary knowledge were and how the teacher overcome students' challenges. The 
theme described and analyzed the recurrent activity, which involves reading a story and other activities. The recurrent activity revealed how deaf students face many challenges in terms of recognizing the parts of speech (e.g., verb, noun, adjective, pronouns etc.). Therefore, the analysis of the reading activity revealed and asserted that these students have a limited development of English; however, they are in the process of developing language but at a slow rate.

For example, the teacher was teaching students specific words taken from a storybook. One of the words was "sway" and the teacher explained what this word meant by moving her body, making facial expressions, and pointing to a picture of a man walking on a wire and swaying back and forth. The teacher asked the students if they walked on a tiny wall, would they sway? No one answered and then one of them said that his dog's tail sways when he plays with him. The teacher then wrote sway on the board in past tense and present tense and wrote "my dog's tail is swaying; the trees swayed on a windy day." She switched her role from teaching vocabulary knowledge to grammar. Interestingly, one student asked why she put "ed" in sway? Clearly, this activity asserted that these students face many obstacles in order to learn basic reading skills. The transcription below communicates how these students encountered difficulties in learning.

...we are working on that it is hard it's very hard because they don't always first of all ASL [American Sign Language] has very different word order so when you go to write or speak they're not necessarily speaking in the correct word order am so we talked about what is noun am and we make list verbs and everything and then we have every specific sentence patterns so we have the subject and verb and then you go down so that they are able to do. Now, they can sometimes I catch them who is the subject if they just tell me the verb and then can go back and say oh wait is [mage or something the subject]. And so they're starting pick up on it and so they can recognize part of speech, but it is challenging again because they're not hearing it like we do all the time.

The students had a hard time understanding a seemingly simple word. Another activity demonstrated that the students encountered obstacles when working to comprehend the word "terrifying", For example, after reading a storybook to the students. At first the students seemed to understand the meaning; however, when the teacher asked them if walking between towers was a terrifying act, two students replied no. The teacher then displayed a picture of two towers with a man walking on a wire between the buildings. Then, the teacher explained that this act was a really terrifying event. She asked the students whether or not it would be terrifying if they saw a child driving a car? All of the students were quiet until eventually one student signed no. The teacher moved from teaching the meaning of "terrifying" to teaching the syllables of word? She asked the students how many syllables were in the word. All of the students were participants in answering this question; however, some answered correctly, and others did not. The transcription illustrates that these students are behind:

Well, I'm linking these vocabulary with state assessments I mean they're on Kindergarten level so the state assessments for fourth grad. I'm working them toward the level being able to work on this fourth grade words, but they haven't made enough progress to be 
able to... I'm not directly teaching vocabulary to the state assessments, but we are working toward that.

The theme asserted that insufficient or limited English language led to misunderstanding the conversation in the classroom. As Vygotsky (1987) indicated, a nonverbal person who is deaf has a deficit imagination because deaf people are not able to develop speech. He argued that if the imagination is not verbal, then the deficit imagination should not be appeared. I agree that imagination is connected with the development of language and during the storybook reading, and I can see that deaf students are not able to imagine the words terrifying and swaying, even with explanation. It seems they have not been exposed to these words the same way as hearing students, because most learning, especially in the first year, is through indirect conversations with parents, playing with peers, conversations, accidental listening, and watching TV and so on (Luckner \& Cooke, 2010). Consequently, deaf students are deprived of these beneficial experiences of developing their language. As Vygotsky (1987) pointed out, there is an absence of imagination because they do not have prior knowledge and vocabulary knowledge about a certain subject, which will affect speech, and this imagination cannot be interpreted via words or signs, thus resulting in a lack of words.

The teacher understood that the students' learning processes, in particular development and acquisition of vocabulary and comprehending the text, was slow and delayed, and so she needed to adjust and adapt her teaching strategy. As she indicated that

... [t]o be an effective teacher, I must adjust and adapt my teaching to meet the needs of my individual students based on their knowledge of a topic...

Also, the theme revealed that the students are able to learn the same as their hearing peers, but they need much more time and have to give more effort. On the other hand, students' progress is similar to the concept of QSH, which is the acquisition of literacy skills by those who are deaf and hard of hearing is qualitatively similar to that of those who have typical hearing. However, quantitatively, it is delayed to the level of someone learning English as a foreign language. Thus, the vocabulary knowledge of deaf and hard of hearing students is less than their typical hearing peers. The QSH strongly believes that students who are deaf and hard of hearing can learn like their hearing peers, but at a slower speed and rate, obtain smaller results in learning, and need additional assistance services.

Therefore, through this learning and teaching setting, the researcher asserted that these students faced many challenges in terms of understanding vocabulary knowledge. However, the teacher adapted and adjusted her teaching before these students engaged in reading the story by giving the students a small number of vocabulary words. Also, these vocabulary words are not on par with hearing students' ability to explain the difference, repeat words, and provide visual means.

\section{Supporting Teacher Needs}

The third theme was developed using informal and formal interviews. The highlighted theme speaks to the additional support the teacher needs in the classroom in order to make the learning environment more effective. Therefore, the additional support the 
teacher needed to assist her in making the learning process meaningful and effective was not available. She indicated during the interview:

The additional support we do have is a person who is doing IEPs [Individualized

Education Programs], but she is an amazing reading teacher, so having her come into the class to model the lesson and talk about vocabulary and sound will be amazing... I think having someone show me would be so much more meaningful than just having that type of support or even having a reading specialist type person who can come to you. Now, I have a wide range of kids. I have kids at higher levels, and I have kids who are at lower levels, and just having someone come and pull kids who need extra help or that type of thing is what they have in regular education. In my old school, they pulled specific kids who were really low, and here, more go into the classroom and work with one class instead of pulling a variety of kids. So, I think we do lack that support.

In addition, the teacher pointed out that she needed more support with technology and trust from the administration. The transcription showed the following:

I would like to see more support with technology and giving us the resources needed to teach effectively. I would also like the administration to understand that deaf children learn differently and trust the teachers with the knowledge to make curriculum decisions.

Thus, the school that provides instructional resources and assistances that teachers need would help to make the learning process go more effectively. In the co-teaching classroom, teachers typically have a general education teacher and a special education teacher, or they have two special education teachers - one has more experience in a certain content area than the other.

Surely, having two teachers in the classroom has many advantages for students and teachers because students will have a chance to learn from two teachers. Additionally, in a dual teaching environment, the teacher can extend her teaching while another teacher works with students who face difficulties. Also, the special education teacher and the general education teacher, or another special education teacher who has more experience than another teacher in a certain subject can help the teacher overcome specific challenges that students encounter. Therefore, co-teaching works because all teachers have strengths and weaknesses, so in the co-teaching environment, the students are fortunate because they have the expertise of two teachers who can enable students to learn more effectively and appropriately.

Also, using technology in the classroom is significantly useful and needed in the $21^{\text {st }}$ century, especially by students who are deaf. The types of technology that are of specific interest to teachers who are deaf or hard of hearing include closed captioning, real time captioning, sound fields, FM systems, speech and speech reading computer programs, computer assisted note taking, and the Internet; these types of technology can facilitate deaf students' learning process. Moreover, advanced technologies such as an iPad have tremendous advantages that improve students' reading skills. At the same time, students can easily access the sound via connecting the iPad's Bluetooth with digital heating aids that contribute to organizing the sound sufficiently and in turn promotes reading skills. Consequently, it is important for schools to dedicate portions of their budgets to allow for such technology in the classroom. 


\section{DISCUSSION}

This ethnographic study explored how the teacher approached teaching new vocabulary knowledge to the students, how the teacher dealt with the challenges encountered by deaf students in order to make the learning process successful, and what kind of support the teacher needed to make the learning environment more effective. Three research questions guided the study to explore these themes in detail.

The recurrent activity in the first theme-reading storybooks—revealed how the teacher was teaching new vocabulary knowledge in the classroom. The teacher's approach to teaching was heavily focused on repetition of words through many recurrent activities. Therefore, the teacher had to move beyond traditional ways of teaching vocabulary that concentrate on only one approach and cannot enable deaf students to move toward ownership of the words. For example, in traditional modes of teaching vocabulary, the teacher may cover a list of vocabulary items that will be valuable for students to know before a reading lesson. When students practice words with signing, fingerspelling, and pronouncing, they are required to use the words in sentences. For instance, "the student might write 'very sad' as a meaning for the word tragic and create a sentence such as the following: "This is a tragic event"' (Paul, 1996, p. 12). Thus, the concentration on meanings in vocabulary lessons does not contribute to the development of depth of vocabulary knowledge. Importantly, students will not be able to acquire words deeply through traditional approaches to teaching vocabulary. Therefore, students need to learn vocabulary lessons through a combination of approaches-including direct instruction and incidental vocabulary instruction. These two approaches allow students to have consistent reoccurring exposure to the words through review and practice. Therefore, if a teacher only concentrates on one approach it might not contribute to students' comprehension of the subject or the aim of the lesson, as the researcher observed in the second theme.

In terms of the second theme, the challenges that deaf and hard-of-hearing students encounter in the classroom, it was clear that the poor reading skills were recurrent as the students read storybooks. There are many reasons for poor reading skills. Luckner et al. (2005/2006) pointed out five obstacles that prevent the development of vocabulary knowledge among deaf and hard-of-hearing students: "a) lack of access to the phonological code, b) limited fluency with the language prior to attending school, c) lack of early literacy experiences prior to entering school, d) a delay in the acquisition of vocabulary, and e) difficulties with lower level reading skills" (p. 444). These points described the obstacles to developing sufficient reading skills. However, this does not mean that the students cannot learn as hearing students do. In fact, deaf or hard of hearing students can learn in the same ways as hearing students with some adaptions and adjustments. Moreover, teachers need to use multiple modes of instruction so that they can attend to everyone's needs rather than focusing only on one approach, which may only reach a few students. Also, the QSH suggests that deaf students are able to learn in qualitatively similar ways to hearing students in terms of their learning process, but quantitatively their learning is delayed compared to hearing students. Therefore, deaf and hard of hearing students need to learn through diverse instructional modes. There is 
support that can help teachers develop lessons with varying instructional tools. The teacher in the research indicated that she needed such support in order to make the learning and teaching in her classroom more effective.

The third theme centered around school support and its correlation with producing an effective learning environment. The kinds of support the teacher needed included collaboration with other teachers in the classroom, as well as help using technology that could enhance her lesson plans. Collaboration or co-teaching has many positive aspects that make lessons more effective and meaningful for students and teachers alike. For example, if two or three students do not understand a certain subject, the co-teaching teacher can easily work with these students to understand the subject without interrupting the primary teacher conducting the lesson. Also, students will get the benefits of learning from two teachers and the co-teaching teacher can become a tutor for students to overcome challenges in learning. There are many ways of implementing these strategies into the classroom.

Likewise, the most effective and meaningful aspect is using technology such as iPads in the classroom, which has many benefits. For example, the teacher can easily connect the students' hearing aids through the iPads in order to enable the students to access sounds clearly, which in turn results in improving the students' speech without requiring the teacher to use visual phonics to teach students. Also, in learning reading skills, students are able to watch videos related to stories, listen to decoding, and play educational games to promote concepts or topics relevant to their lessons. Applying instructional technology in the classroom can be beneficial for deaf students.

\section{CONCLUSION}

The most significant conclusion to be drawn from this study is that few researchers have utilized ethnographic methods to provide information about how vocabulary is learned and taught with deaf and hard-of-hearing students in the classroom. An ethnographic approach can provide insights into the learning and teaching of vocabulary that quantitative methods alone cannot illustrate. Also, immersion in the school environment allows researchers to understand complex issues that cannot be observed or explained via other types of research. Thus, this study will open doors for other researchers who are interested in implementing ethnographic approaches in order to identify teaching strategies for introducing new vocabulary knowledge, understand students' progress and challenges in learning new vocabulary knowledge, and recognize what kinds of classroom support teachers need.

\section{FUTURE RESEARCH AND RECOMMENDATIONS}

The limitation of this study its length, as that impacted how much time of I collected the data. The research was based on four visits. More time may have offered a larger range of hearing loss in students. Another limitation was that the study focused so closely on just one classroom means results cannot be generalized since deaf and hard or hearing students are very diverse. Their hearing loss ranges from mild to severe. Additionally, the philosophy for teaching the deaf and hard of hearing students is also varied because their hearing losses are not stable and so multiple systems are therefore needed, such as Pidgin Signed English (PSE), American Sign Language (ASL), Aural/Oral, and Total 
Communication (TC) and other visual communications. Thus, this study needs to be implemented over many philosophies for teaching in order to obtain a holistic view of teaching strategies of teachers of deaf and hard-of-hearing students.

\section{REFERENCES}

de Villiers, P. A., \& Pomerantz, S. B. (1992). Hearing impaired students learning ne words from written context. Applied Psycholinguistics, 13 409-431.

Curtis, M. (2006). The role of vocabulary instruction in adult basic education. Annual review of adult learning and Literacy.

Davis, F. B. (1944). Fundamental factors of comprehension in reading. Psychometrika, 9, 3 , 185-197.

Hamm, L. D. (2010). We can read and write: Critical characteristics of highly literate deaf and hard of hearing students and their families (Doctoral dissertation). Retrieved from http://digitallibrary.usc.edu/assetserver/controller/item/etd-Hamm-3620.pdf

Lave, J., \& Wenger, E. (1991). Situated learning: Legitimate peripheral participation. New York: Cambridge University Press.

Lederberg, A. R., \& Spencer, P. E. (2001). Vocabulary development of deaf and hard of hearing children. In M. D. Clark, M. Marschark, \& M. Karchmer (Eds.), Context, cognition, and deafness (pp. 88-112). Washington, DC: Gallaudet University Press.

Lee, C. D., \& Smagorinsky, P. (Eds.). (2000). Vygotskian perspectives on literacyresearch: Construction meaning through collaborative inquiry. New York: Cambridge University Press.

Luckner, J., Sebald, A., Cooney, J., Young, J., \& Muir, S. (2005/2006). An examination of the evidence-based literacy research in deaf education. American Annals of the Deaf, 150(5), 443-56.

Luckner, J., \& Handley, C. (2008). A summary of the reading comprehension research undertaken with students who are deaf or hard of hearing. American Annals of the Deaf, 153(1), 6-36. Retrieved from http://muse.jhu.edu

Luckner, J., \& Cooke, C. (2010). A summary of the vocabulary research with students who are deaf or hard of hearing. American Annals of the Deaf, 155(1), 38-67. doi:10.1353/aad.0.0129

Mayer, C., \& Wells, G. (1996). Can the linguistic interdependence theory support a bilingual-bicultural model of literacy education for deaf students? Journal of Deaf Studies and Deaf Education, 1(2), 93-107.

McKeown, M. G., \& Beck, I. L. (1988). Learning vocabulary: Different ways for different goals. Remedial and Special Education, 9, 1, 42-46.

Marschark, M., Lang, H. G., \& Albertini, J. A. (2002). Educating deaf students: From

research to practice. New York, NY: Oxford Press, Inc.

Nagy, W. (2005). Why vocabulary instruction needs to be long-term and comprehensive. In E. H. Hiebert \& M. L. Kamil (Eds.), Teaching and learning vocabulary: Bringing research to practice (pp. 27-44). Mahwah, NJ: Lawrence Erlbaum Associates, Inc.

National Reading Panel (U.S.), \& National Institute of Child Health and Human Development (U.S.). (2000). Report of the National Reading Panel: Teaching children to 
read: An evidence-based assessment of the scientific research literature on reading and its implications for reading instruction: Reports of the subgroups. Washington, D.C.: National Institute of Child Health and Human Development, National Institutes of Health.

Paul, P. (1989). Depth of vocabulary knowledge and reading. Intervention in school and clinic (1053-4512), 25 (1), p. 13.

Paul, P. V., Stallman, A. C., \& O'Rourke, J. P. (1990). Using three test formats to assess good and poor readers' word knowledge. (Technical Report No. 509). Urbana, IL: Center for the Study of Reading.

Paul, P. (1996). Reading vocabulary knowledge and deafness. Journal of Deaf Studies and Deaf Education, 1(1), 3-15.

Paul, P. V. (1998). Literacy and deafness: The development of reading, writing, and literate thought. Boston: Allyn and Bacon.

Paul, P. V. (2009). Language and deafness $\left(4^{\text {th }}\right.$ ed). Sudbury, MA: Jones and Bartlett Publishers, LLC.

Paul, P. (2010). The Qualitative Similarity Hypothesis. In R. Nata (Ed.), Progress in education (Vol. 20, pp. 1-31) New York, NY: Nova Science.

Paul, P, \& Lee, C. (2010). The Qualitative Similarity Hypothesis. American Annals of the Deaf, 154(5), 456-462.

Paul, P. (2012). The Qualitative Similarity Hypothesis. In P. Paul \& D. Morres (Eds.), Deaf epistemologies: Multiple perspectives on acquisition of knowledge (pp. 179- 198). Washington, DC: Gallaudet University Press.

Paul, P., \& Wang, Y. (2012). Literate thought: Understanding comprehension and literacy. Sudbury, MA: Jason \& Bartlett Learning.

Qian, D. (1999). Assessing the role of depth and breadth of vocabulary knowledge in reading comprehension. The Canadian Modern Language Review, 56, 282-308

Singleton, J. L., Morgan, D., DiGello, E., Wiles, J., \& Rivers, R. (2004). Vocabulary use by low, moderate, and high ASL-proficient writers compared to hearing ESL and monolingual speakers. Journal of Deaf Studies and Deaf Education, 9(1), 86-103. doi:10.1093/deafed/enh011

Stewart, D., \& Clarke, B. (2003). Literacy and your deaf child: What every parent should know. Washington, DC: Gallaudet Press.

Spencer, L. J., \& Tomblin, J. B. (2009). Evaluating phonological processing skills in children with prelingual deafness who use cochlear implants. Journal of Deaf

Studies and Deaf Education, 14(1), 1-21. doi:10.1093/deafed/enn013

Stahl, S., \& Nagy, W. (2006). Teaching word meanings. Mahwah, NJ: Erlbaum.

Trezek, B. J., Wang, Y., \& Paul, P. V. (2010). Reading and deafness: Theory, research, and practice. Clifton Park, NY: Delmar/Cengage Learning

Vygotsky, L. S. (1978). Mind in society: The development of higher psychological processes. Cambridge: Harvard University Press.

Williams, C. (2012). Promoting vocabulary learning in young children who are d/Deaf and hard of hearing: Translating research into practice. American Annals of the Deaf, 156(5), 501-508. 